\title{
Unique Properties of NMDA Receptors Enhance Synaptic Excitation of Radiatum Giant Cells in Rat Hippocampus
}

\author{
Eilon D. Kirson and Yoel Yaari \\ Department of Physiology, Institute of Medical Sciences, The Hebrew University-Hadassah Faculty of Medicine, \\ Jerusalem 91120, Israel
}

In the hippocampus, fast excitatory synaptic transmission of principal projection neurons is mediated by non-NMDA glutamate receptors, whereas NMDA glutamate receptors serve a slower modulatory role. We used the whole-cell patch-clamp technique in adult hippocampal slices to assess the role of NMDA receptors in synaptic excitation of a recently discovered excitatory projection neuron, the $\mathrm{CA} 1$ radiatum giant cell (RGC). Glutamatergic synaptic activation, even after blocking nonNMDA receptors, fired an NMDA receptor-dependent burst of action potentials in RGCs. In contrast, the contribution of NMDA receptors to synaptic activation of pyramidal cells (PCs)

Neurons in the hippocampus are traditionally subdivided into two main classes, namely, principal (or projection) neurons and interneurons (or local circuit neurons). In the hippocampus proper (Ammon's horn), the principal neurons are the excitatory pyramidal cells (PCs), whose somata are located in a well defined cellular layer (stratum pyramidale). In addition to ramifying locally, their axons project out of the hippocampus to other cortical and subcortical structures. By contrast, the interneurons form a heterogeneous group of nonpyramidal cells, which are mostly inhibitory in function. They are widely dispersed in all hippocampal layers, but their axonal ramifications are generally contained within distinct hippocampal regions (Ramon y Cajal, 1968; Freund and Buzsaki, 1996).

Recently, a specific type of nonpyramidal hippocampal neuron, the radiatum giant cell (RGC), hitherto considered an interneuron (Amaral and Woodward, 1977; Lang and Frotscher, 1990; Maccaferri and McBain, 1996), was found to project out of the hippocampus to the olfactory cortex. Furthermore, this neuron was found to resemble PCs, rather than other interneurons, in several distinctive morphological and functional features. First, it has spiny dendrites and a myelinated axon. Second, its axon collaterals in stratum oriens form asymmetric (presumably excitatory) synapses (Gulyas et al., 1998). Third, it manifests a prominent spike afterdepolarization (ADP) and displays spike frequency accommodation (Maccaferri and McBain, 1996). Finally, it expresses monosynaptic long-term potentiation (LTP), unlike

Received Jan. 3, 2000; revised April 6, 2000; accepted April 14, 2000.

This work was supported by grants from the German Israeli Foundation for Scientific Research and Development, the German Bundesministerium für Bildung und Forschung, the Israeli Ministry of Science, and the Israel Science Foundation founded by the Israel Academy of Sciences and Humanities. E.D.K. was supported by a fellowship from Teva Pharmaceuticals Inc.

Correspondence should be addressed to Dr. Yoel Yaari, Department of Physiology, Institute of Medical Sciences, The Hebrew University-Hadassah Faculty of Medicine, P.O. Box 12272, Jerusalem 91120, Israel. E-mail: yaari@md2.huji.ac.il. Copyright (C) 2000 Society for Neuroscience $0270-6474 / 00 / 204844-11 \$ 15.00 / 0$ was minimal. Stimulation of the same synaptic inputs evoked greater than threefold larger EPSCs in RGCs than in PCs. Isolated NMDA receptor-mediated EPSCs were significantly less sensitive to blockade by extracellular $\mathrm{Mg}^{2+}$ and had slower decay kinetics in RGCs than in PCs. Thus, unique properties of synaptic NMDA receptors underlie enhanced synaptic excitability in a newly discovered excitatory hippocampal projection neuron.

Key words: radiatum giant cell; NMDA; magnesium sensitivity; EPSC; hippocampus; rat other interneurons, which undergo long-term depression when activated at high frequency (Maccaferri and McBain, 1996). Thus, RGCs most likely represent a novel type of excitatory hippocampal projection neuron (Gulyas et al., 1998).

To characterize the contribution of RGCs to signal transmission through the hippocampus, we have now investigated their synaptic recruitment by afferent fibers. In hippocampal CA1 PCs, EPSPs consist of a fast and a slow component, mediated by AMPA and NMDA receptors, respectively. In normal conditions, NMDA receptors contribute minimally to the EPSP (Andreasen et al., 1989), because of their effective blockade by $\mathrm{Mg}^{2+}$ ions at resting membrane potential (Mayer et al., 1984; Nowak et al., 1984). Thus, synaptic excitation of the PCs is mediated primarily by AMPA receptors, whereas NMDA receptors are thought to play a modulatory role, e.g., induction of LTP (Bliss and Collingridge, 1993). Here we report that NMDA receptors in RGCs have unique properties that allow their recruitment already at resting membrane potential. Consequently, NMDA receptors make a major contribution to synaptic excitation of these neurons, not previously seen in other types of hippocampal neurons (Collingridge et al., 1983; Hestrin et al., 1990; Sah et al., 1990; Keller et al., 1991; Perouansky and Yaari, 1993).

\section{MATERIALS AND METHODS}

Slice preparation. Experiments were performed on thin hippocampal slices obtained from adult $(>150 \mathrm{gm})$ Sabra rats. Methods for preparation of thin slices were similar to those described previously (Edwards et al., 1989; Kirson and Yaari, 1996). Briefly, rats were anesthetized with isoflurane (3-4\%) and decapitated with a guillotine. The brain was removed and immediately immersed in ice-cold oxygenated $\left(95 \% \mathrm{O}_{2}, 5 \%\right.$ $\mathrm{CO}_{2}$ ) dissection saline. The caudal two-thirds of one hemisphere (containing one hippocampus) were glued to the stage of a vibratome (Campden Instruments). Transverse slices, $250 \mu \mathrm{m}$ thick, were cut from the region of the hemisphere containing the anterior hippocampus. The hippocampal portion was dissected out of each slice and transferred to an incubation chamber containing the oxygenated incubation saline at $34^{\circ} \mathrm{C}$. In some experiments the CA3 region was cut from the slice under a dissecting microscope. After an incubation period of $1 \mathrm{hr}$, slices were 
transferred, one at a time, to a recording chamber where they were continuously perfused $(2.5 \mathrm{ml} / \mathrm{min})$ with oxygenated experimental saline at room temperature $\left(21-24^{\circ} \mathrm{C}\right)$.

Solutions and drugs. The dissection saline consisted of (in $\mathrm{mm}$ ): $\mathrm{NaCl}$, 125; KCl, 2.5; $\mathrm{NaHCO}_{3}, 26.7$; HEPES, 13; $\mathrm{NaH}_{2} \mathrm{PO}_{4}, 1.25$; glucose, 12.5; $\mathrm{CaCl}_{2}, 0.5$; and $\mathrm{MgSO}_{4}, 4, \mathrm{pH}$ 7.3. The incubation saline was identical except for $\mathrm{NaHCO}_{3}, 22.5 \mathrm{~mm}$. The standard experimental saline consisted of (in mM): NaCl, 125; $\mathrm{KCl}, 2.5 ; \mathrm{NaHCO}_{3}, 26.7 ; \mathrm{CaCl}_{2}, 2.5$; $\mathrm{MgCl}_{2}, 1$; HEPES, 13; and glucose, 12.5. The $\mathrm{pH}$ was 7.3, and osmolarity was 300 mOsm. In $\mathrm{Mg}^{2+}$-free saline, $\mathrm{MgCl}_{2}$ was omitted. All salines also contained glycine $(5 \mu \mathrm{M})$ to saturate the glycine binding sites in NMDA receptors. For current-clamp experiments the intracellular (pipette) solution consisted of (in mM): K-gluconate, 120; EGTA, 1; HEPES, 10; $\mathrm{MgCl}_{2}, 2$; $\mathrm{NaCl}, 4$; and $\mathrm{CaCl}_{2}$, 1. For voltage-clamp experiments the pipette solution consisted of (in $\mathrm{mM}$ ): $\mathrm{CsF}, 110$; tetraethylammonium, 20; 1,2-bis( $o$-aminophenoxy)ethane- $N, N, N^{\prime}, N^{\prime}$-tetra-acetic acid, 10; HEPES, $10 ; \mathrm{MgCl}_{2}, 2$; and $\mathrm{NaCl}, 4$. In both cases the $\mathrm{pH}$ was 7.3 , and osmolarity was 300 mOsm. Biocytin $(0.5 \%)$ was added routinely to the pipette solution. In some experiments, bicuculline, D,L-2-amino-5-phosphono-valeric acid (APV), and/or 6-cyano-7-nitro-quinoxaline-2,3-dione (CNQX) were applied via the bath. Chemicals and drugs were purchased from Sigma (Rehovot, Israel) with the exception of CNQX (Research Biochemicals, Natick, MA).

Whole-cell recordings. Cells in the CA1 field were visualized at $400 \times$ magnification with Dodt-Gradient-Contrast optics (Luigs \& Neumann, Ratingen, Germany) using a Zeiss (Thornwood, NY) Axioskop microscope and an infrared video camera (Hamamatsu, Hamamatsu City, Japan). The PCs were identified by their position in stratum pyramidale, the pyramidal shape of their somata, and their prominent apical dendrite. The RGCs were identified by their location in stratum radiatum, the unusually large dimensions of their somata and the one to two prominent dendrites directed toward the stratum lacunosum-moleculare. All cells were also filled with biocytin for post hoc identification.

Recording pipettes were pulled from borosilicate glass on a vertical puller (List Medical) and coated with SYLGARD resin (Dow Corning, Midland, MI). Pipette resistances varied between 1.5 and $4 \mathrm{M} \Omega$ when filled with intracellular solution. In voltage-clamp experiments, after establishing the whole-cell recording configuration, series resistance was compensated for by setting the series resistance compensation control of the amplifier (Axopatch 200A; Axon Instruments, Foster City, CA) to $75-95 \%$. Experiments in which the series resistance exceeded $20 \mathrm{M} \Omega$ were discarded. Synaptic responses were obtained by applying $40 \mu \mathrm{sec}$ voltage pulses $(1-70 \mathrm{~V})$ through a bipolar stimulation electrode. The electrode was positioned in the stratum radiatum $\sim 200 \mu \mathrm{m}$ from the cell toward CA3 to activate afferent fibers to CA1 neurons (Schaffer collaterals and commissural axons; Traub and Miles, 1991).

Synaptic $I-V$ curves were determined as follows. Cells were held at $-60 \mathrm{mV}$ and sequentially stepped to holding potentials between -90 and $+30 \mathrm{mV}$. The cells were held at each potential for $30 \mathrm{sec}$ before recording synaptic currents to allow for inactivation of voltage-activated currents. Synaptic currents were evoked at $10 \mathrm{sec}$ intervals. Five consecutive responses to synaptic stimulation were averaged at each holding potential. The $I-V$ relations were constructed by plotting the amplitude of the average synaptic current response versus holding potential.

Cell staining. For conclusive cell identification, recordings were made with biocytin-containing pipettes. Biocytin entered the cells by passive diff usion. In a given slice only one putative PC and/or RGC were stained. After the experiment the slices were fixed overnight in $4 \%$ paraformaldehyde and incubated with avidin-biotin complex (Vectastain ABC Elite kit; Vector Laboratories, Burlingame, CA). The stained cells were photographed at $200 \times$ magnification. Drawings of RGC morphology were obtained by manual retracing of scanned photographs of the cells.

Data analysis. Recordings were filtered on-line at $5 \mathrm{kHz}$, digitized at a sampling rate of $10 \mathrm{kHz}$, and analyzed off-line using a Pentium personal computer and software from Axon Instruments. Active and passive intrinsic properties were measured as described previously (Jensen et al., 1996). Briefly, spike threshold was defined as the membrane potential at which the slope of the voltage trace increased abruptly during membrane charging induced by positive current pulses. Spike amplitude was measured as the voltage difference between the peak of the action potential and resting membrane potential $\left(V_{\mathrm{m}}\right)$. Spike half-width was calculated as spike duration at $50 \%$ of the spike amplitude. Passive membrane properties were measured by injecting small (0.1-0.5 nA) negative current pulses $400 \mathrm{msec}$ long into the cell. The input resistance was calculated by plotting the steady-state voltages versus current amplitudes and measur- ing the slope of a linear regression of the plot. The membrane time constant was measured by fitting a single exponential function to the slow phase of the charging curve produced by application of the smallest negative current pulse. Analyses of evoked EPSCs were performed on averages of 5-10 consecutive traces. The rise times of EPSCs were measured as the time from 10 to $90 \%$ of the peak current. The decay phase of the EPSCs was fitted with the sum of two exponential functions:

$$
y(t)=A_{\mathrm{f}} \cdot e^{-t / \tau_{\mathrm{f}}}+A_{\mathrm{s}} \cdot e^{-t / \tau_{\mathrm{s}}},
$$

where $y$ is the current amplitude at a given time $(t), A$ is the peak current amplitude, $\tau$ is the decay time constant, and the subscripts $f$ and $s$ denote fast and slow components, respectively.

The empirical relations between NMDA receptor-mediated EPSCs (NMDA EPSCs) and membrane voltage ( $I-V$ relations) were fitted with a modification of the theoretical function describing the voltage dependence of NMDA receptor-mediated currents (Perouansky and Yaari, 1993):

$$
I(V)=\frac{a \cdot g_{\max }\left(V-V_{\mathrm{r}}\right)}{\left(a+\left[\mathrm{Mg}^{2+}\right] \cdot e^{-b V} \cdot e^{-c V^{2}}\right)},
$$

where $I$ represents the peak amplitude of the EPSC at a given membrane potential $(V), g_{\max }$ is the maximal conductance, $V_{\mathrm{r}}$ is the reversal potential of the EPSC, $\left[\mathrm{Mg}^{2+}\right]$ is the extracellular $\mathrm{Mg}^{2+}$ concentration, and $a$, $b$, and $c$ are constant parameters. The modification of the function is based on the assumption that the logarithm of $K_{\mathrm{d}}$ for $\mathrm{Mg}^{2+}$ binding is related to membrane potential by a second-order linear function (Kuner and Schoepfer, 1996; Kirson et al., 1999). That is:

$$
\log \left(K_{\mathrm{d}}\right)=a+b \cdot V+c \cdot V^{2} .
$$

To asses the relative position of the $\mathrm{Mg}^{2+}$ binding site within the transmembrane electric field, the voltage dependence of $\mathrm{Mg}^{2+}$ block of NMDA receptors was quantified by replacing this empirical secondorder linear function with the Woodhull equation (Woodhull, 1973):

$$
K_{\mathrm{d}}=K_{\mathrm{d}(0 \mathrm{mV})} \cdot \exp \left(\frac{z \delta V F}{R T}\right)
$$

where $\delta$ is the fraction of the electric field experienced by a $\mathrm{Mg}^{2+}$ ion, $z$ is valence, $V$ is membrane potential, $K_{\mathrm{d}(0 \mathrm{mV})}$ is the affinity of the NMDA receptor to $\mathrm{Mg}^{2+}$ at $0 \mathrm{mV}$, and $R, T$, and $F$ have their usual meanings.

Data are presented as mean \pm SE. Significant differences between groups of samples were tested with Student's $t$ test, Mann-Whitney $U$ test, or Wilcoxon paired test. A significance level of $\alpha=0.05$ was used in all tests. Fitting procedures used the Marquardt-Levenberg algorithm to seek parameter values that minimize the sum of the squared differences between the observed and predicted values of the dependent variables.

\section{RESULTS}

\section{Morphological characterization of RGCs}

Whole-cell patch-clamp recordings and biocytin stainings were obtained from a total of 72 neurons, of which 30 were identified as PCs and 39 as RGCs. Three neurons in stratum radiatum appeared multipolar after staining and were discarded from the present study. They were probably multipolar inhibitory interneurons (Freund and Buzsaki, 1996).

Some of the morphological differences between PCs and RGCs are portrayed in Figure 1. As seen in the photomicrograph of a typical PC (Fig. 1A), the soma of the neuron is located in the stratum pyramidale. Its thick apical dendrite reaches into the stratum radiatum and lets off several secondary and tertiary thin dendritic processes, whereas its basilar dendrites branch extensively in the stratum oriens. In contrast, the photomicrograph of a typical RGC (Fig. $1 B$ ) shows that its large, triangular cell body is located in the stratum radiatum. Its two apical dendrites ascend toward the stratum lacunosum-moleculare and arborize extensively. The axon of the RGC arises vertically, traversing the stratum pyramidale and bifurcating in the stratum oriens into two 
A

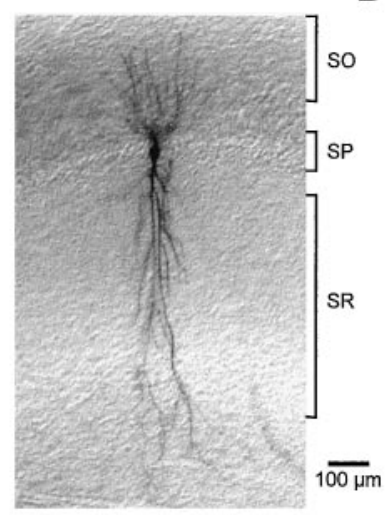

B

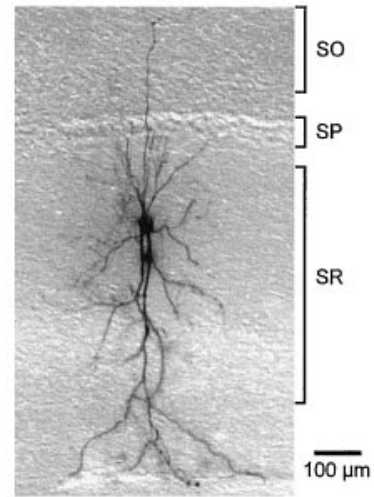

C

a

b

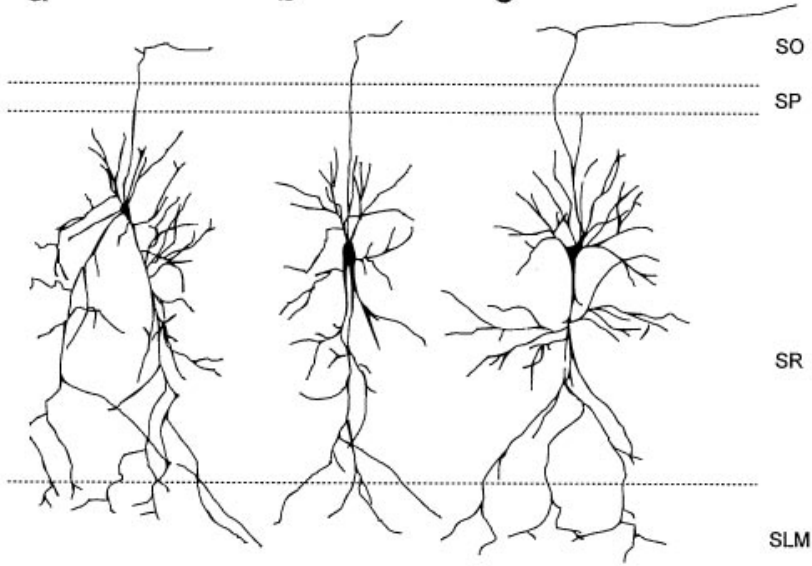

$\overline{100 \mu \mathrm{m}}$
Table 1. Passive and active membrane properties of RGCs versus PCs

\begin{tabular}{lcc} 
& RGCs $(n=7)$ & PCs $(n=8)$ \\
\hline Input resistance $(\mathrm{M} \Omega)$ & $86 \pm 11$ & $100 \pm 24$ \\
Time constant $(\mathrm{msec})$ & $50 \pm 3$ & $39 \pm 6$ \\
Membrane potential $(\mathrm{mV})$ & $-63 \pm 1$ & $-65 \pm 1$ \\
Spike threshold $(\mathrm{mV})$ & $-31 \pm 3$ & $-38 \pm 3$ \\
Spike amplitude $(\mathrm{mV})$ & $139 \pm 8$ & $136 \pm 4$ \\
Spike half-width $(\mathrm{msec})$ & $1.9 \pm 0.09$ & $1.9 \pm 0.1$ \\
\hline
\end{tabular}

A

B
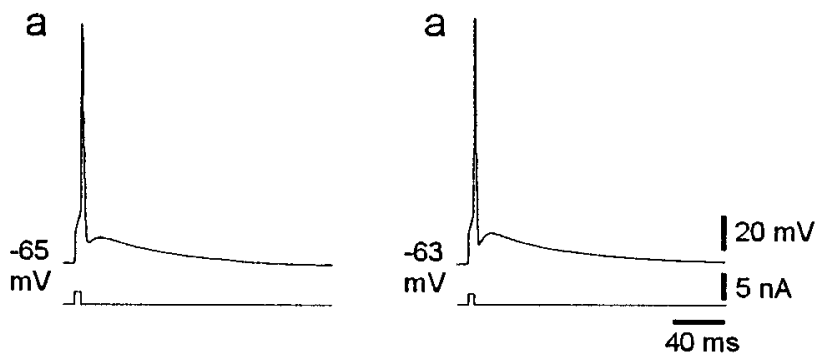

b

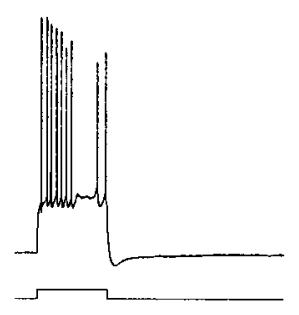

b

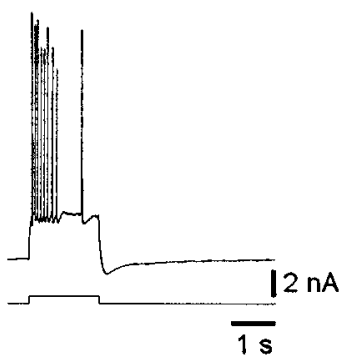

Figure 1. Morphological features of RGCs. $A, B$, Photomicrographs of an exemplary biocytin-stained PC and RGC, respectively. $C$, Manual tracings of three morphologically different RGCs. The distinguishing morphology of each neuron is based on the shape of the dendritic tree, as described in Results. Note that the tracing in $b$ is of the same cell shown in $B$. SO, Stratum oriens; $S P$, stratum pyramidale; $S R$, stratum radiatum; $S L M$, stratum lacunosum-moleculare.

main branches, which extend in opposite directions toward the subiculum and the fimbria (Fig. $1 C$ ).

As recently described (Gulyas et al., 1998), the RGCs varied in their dendritic morphologies The three most prevalent subtypes, which were present in similar proportions, are shown in Figure $1 C$. The first type had two thick and symmetrical apical dendrites, which branched off directly from the soma at a wide angle between each other (Fig. $1 C, a$ ). The second type had one main apical dendrite and a secondary shorter dendrite, which branched off directly from the soma in parallel to the main dendrite (Fig. $1 C$, $b$ ). The third type was morphologically similar to a PC, having one apical dendrite, which bifurcated distal to the soma (Fig. $1 C, c$ ).

\section{Intrinsic properties of RGCs versus PCs}

We used current-clamp recordings to measure the resting membrane potential, input resistance, and time constant, as well as the threshold, amplitude, and half-width of the action potential in both cell types in standard saline. No significant differences were found between PCs $(n=8)$ and RGCs $(n=7)$ in these passive and active membrane properties (Table 1). Likewise, both PCs and RGCs fired a single action potential in response to a brief (5

Figure 2. PCs and RGCs have similar intrinsic firing patterns. Currentclamp recordings were obtained from an exemplary PC $(A)$ and $\operatorname{RGC~}(B)$. The characteristic firing response to brief $(5 \mathrm{msec})$ and long $(1600 \mathrm{msec})$ positive current pulses are shown in $a$ and $b$, respectively. Both the PC and the RGC fired a single action potential in response to brief current pulses and an accommodating train of action potentials in response to long current pulses. The resting potentials of the neurons in this and in the following figures is indicated to the left of the top traces.

msec) depolarizing current pulse. In both cases the spike repolarized incompletely and was followed by an active (i.e., redepolarizing) ADP (Fig. 2A,B,a). In response to long (1600 msec) depolarizing current pulses, both cells fired repetitively at a decrementing frequency (Fig. $2 A, B, b$ ).

\section{Enhanced synaptic excitation of RGCs}

We compared the responses of six PCs versus six RGCs to afferent fiber stimulation in normal saline. Representative responses to different stimulus intensities (varied between 3 and 70 $\mathrm{V}$ ) are shown in Figure 3. For a given stimulus intensity, the responses of the RGC (Fig. $3 B$ ) were always larger than those of the PC (Fig. $3 A$ ). Whereas the PC fired maximally one spike (Fig. $3 A, d, e$ ), the RGC generated up to three action potentials (Fig. $3 B, d, e)$. In the latter case, the spikes rode on a protracted EPSP lasting $>1 \sec ($ Fig. $3 B, e$ ). Similar responses were obtained in all other PCs and RGCs examined. Thus, in standard saline, the maximal number of spikes evoked synaptically ranged between 1 and 4 in RGCs and between 1 and 2 in PCs and was significantly 
A

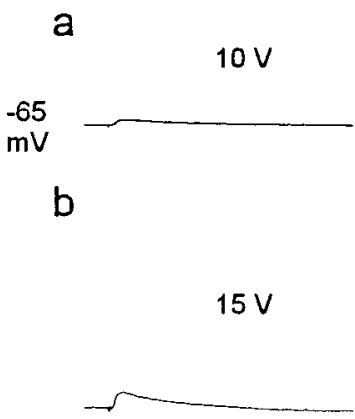

C

$30 \mathrm{~V}$

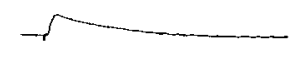

d

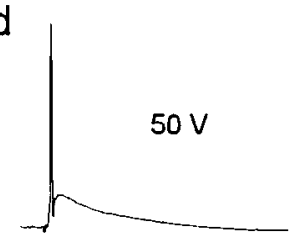

e

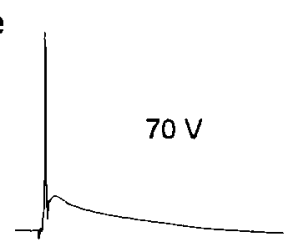

B

a

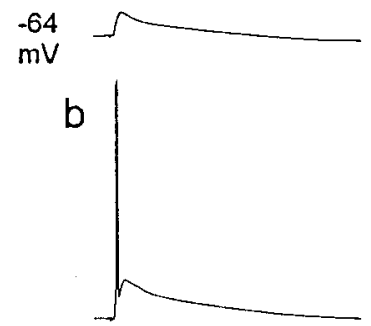

C

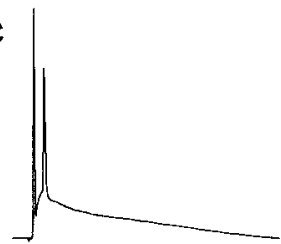

d

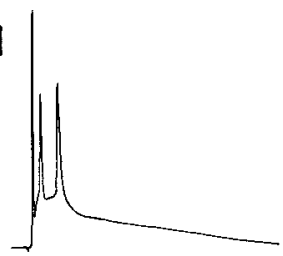

e

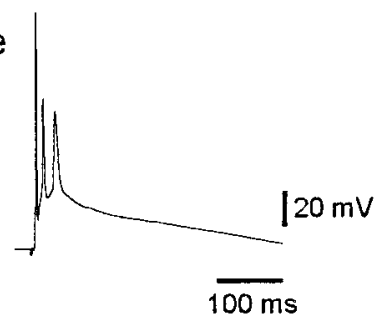

Figure 3. Orthodromic stimulation evokes enhanced excitatory synaptic responses in RGCs. Current-clamp recordings were made in a $\mathrm{PC}(A)$ and an RGC $(B)$ in slices perfused with standard saline. The traces in $a-e$ show the responses of the neurons to afferent fiber stimulation at the indicated intensities. The PC fired only one action potential even at maximal stimulation intensities $(\geq 50 \mathrm{~V})$. In contrast, the RGC was more easily recruited by stimulation and fired a stimulus-graded burst of action potentials.

higher in RGCs than in PCs $(2.3 \pm 0.4$ vs $1.6 \pm 0.25$, respectively).

\section{Effects of disinhibition}

Because afferent fiber stimulation also activates feedforward and feedback inhibition in CA1 (Freund and Buzsaki, 1996), the differential synaptic responses of PCs versus RGCs may be attributable to differences in conjointly activated inhibitory synaptic inputs. Therefore, we compared the synaptic responses of these neurons also after bath application of the $\mathrm{GABA}_{\mathrm{A}}$ receptor antagonist bicuculline $(10 \mu \mathrm{M})$. Representative results in a PC and an RGC are shown in Figure $4, A$ and $B$. In the PC, adding bicuculline to the saline prolonged the EPSPs but did not augment the number of spikes evoked (Fig. $4 A$, compare $a, b$ ). By contrast, bicuculline enhanced the evoked burst responses in RGCs (Fig. 4B, compare panels $a, b$ ).

A

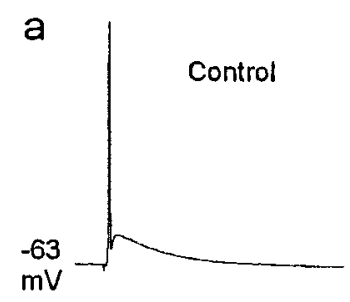

B
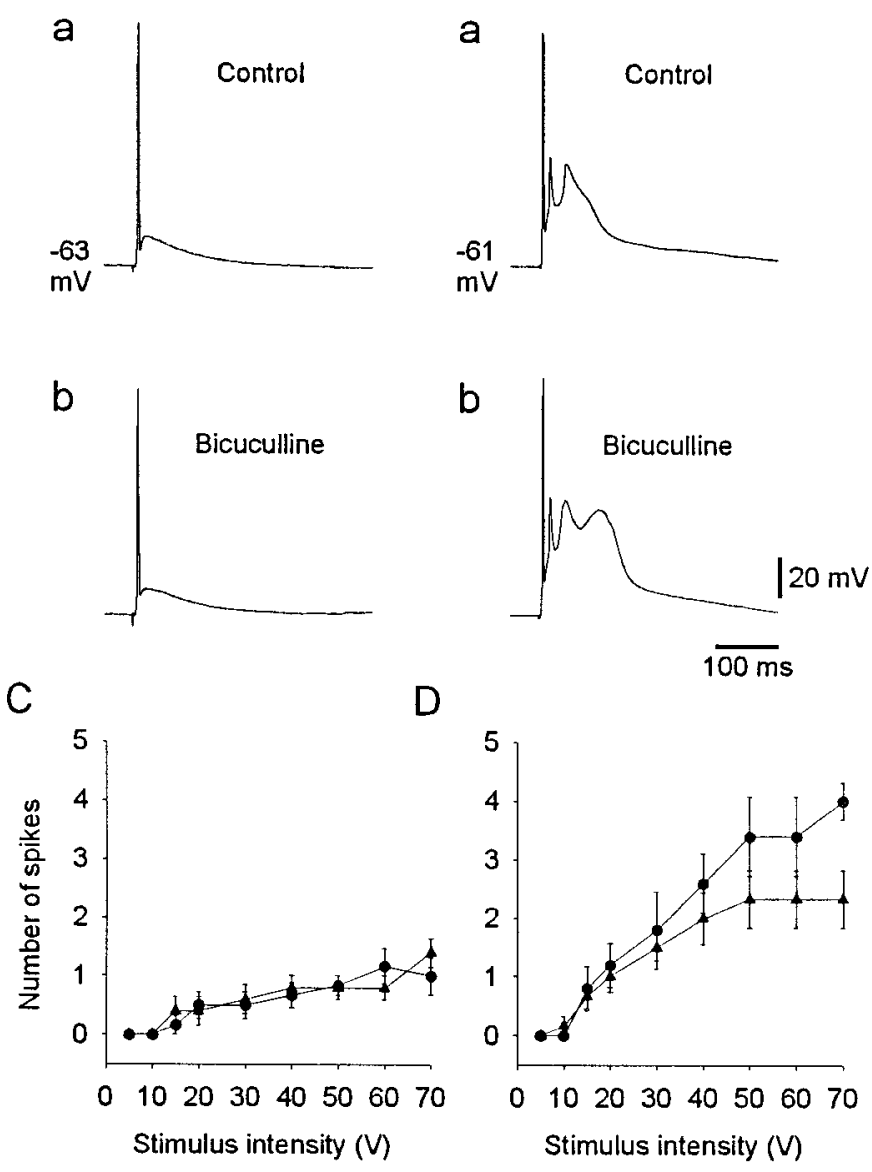

Figure 4. The enhanced synaptic excitability of RGCs versus PCs is not attributable to differences in $\mathrm{GABA}_{\mathrm{A}}$-ergic inhibition. Current-clamp recordings were made in a $\mathrm{PC}(A)$ and an RGC $(B)$. Both cells were stimulated at $50 \mathrm{~V}$. In standard saline, the PC generated a single spike $(A$, $a)$, whereas the RGC fired a spike burst $(B, a)$. After adding $10 \mu \mathrm{M}$ bicuculline to the salines, the discharge of the PC did not change, although the underlying EPSP was enhanced $(A, b)$. In contrast, the discharge of the RGC was enhanced from three to four spikes $(B, b)$. $C$, Graphs of the mean \pm SE number of spikes generated in PCs $(n=5)$ versus stimulus intensity (input-output relations) in standard saline (triangles) and in bicuculline-containing saline (circles). $D$, Same as in $C$, but for RGCs $(n=$ 5). Note in $C$ and $D$ that adding bicuculline does not affect the inputoutput relation of the PCs but enhances the output of the RGCs.

The averaged results from six PCs and six RGCs are shown in Figure 4, $C$ and $D$. Each graph depicts the number of evoked spikes as a function of stimulus intensity (input-output relation). In standard saline, the RGCs generated more spikes than the PCs at all stimulus intensities. Adding bicuculline did not significantly change the input-output relation in PCs (Fig. $4 C$ ), indicating that inhibitory inputs do not strongly modulate the PC output at low-frequency orthodromic stimulation. In contrast, adding bicuculline caused the input-output relation in RGCs to become significantly steeper, so that more action potentials were evoked for a given stimulus intensity. Thus, even at low frequencies of stimulation, conjointly activated inhibitory inputs curtail the excitatory synaptic response in RGCs.

Taken together, these data indicate that the stronger synaptic excitation of RGCs versus PCs is not attributable to weaker inhibitory inputs onto the RGCs. Rather, it reflects more efficacious synaptic excitation of RGCs versus PCs. 


\section{Effects of glutamate receptor antagonists}

To find whether a specific glutamate receptor is involved in the enhanced synaptic excitation of RGCs, we examined the effects of NMDA and non-NMDA receptor blockers on evoked synaptic responses in slices disinhibited with bicuculline. Application of the NMDA receptor antagonist APV $(100 \mu \mathrm{M})$ affected the PC response very little (Fig. $5 A$, compare $a, b$ ), reducing the late EPSP component without affecting the early spike. The early spike response in RGCs also was not affected by APV. However, APV completely suppressed the burst response that followed the first evoked spike (Fig. 5B, compare $a, b$ ). These data suggested that the delayed enhanced response in RGCs is mediated by NMDA receptors. Consistent with this notion, we found that application of the non-NMDA receptor antagonist CNQX (15 $\mu \mathrm{M})$ suppressed the early component of the evoked synaptic response in both $\mathrm{PCs}$ and RGCs, without interfering with the delayed burst response in RGCs (Fig. 5A,B, compare $b, c$ ). The latter response in RGCs was abolished by adding APV $(100 \mu \mathrm{M})$ to the CNQX-containing saline (Fig. $5 B, d$ ).

The results obtained in the six PCs and six RGCs subjected to the excitatory receptor antagonists in disinhibited slices are summarized in Figure 5, $C$ and $D$. The output of the PCs was not significantly affected by APV but was completely suppressed by CNQX (Fig. 5C). This is consistent with the known predominant role of non-NMDA receptors in low-frequency synaptic activation of these neurons (Andreasen et al., 1989; Hestrin et al., 1990; Sah et al., 1990; Perouansky and Yaari, 1993). In contrast, the output of the RGCs was significantly reduced by APV to values well below those obtained in slices with intact inhibition (Fig. 5D). Thus, NMDA receptors contribute to synaptic recruitment of RGCs whether GABA $_{A}$-ergic inhibition is operative or not.

After blocking non-NMDA receptors with CNQX, RGCs still fired a graded spike response to increasing afferent stimulation intensity (Fig. 5D). Although stronger stimuli were required to trigger spikes, the maximal number of spikes was not significantly different from that in control. The output of the RGCs was suppressed completely by additionally blocking NMDA receptors with APV (Fig. 5D). In marked contrast, NMDA receptormediated EPSPs (isolated by adding CNQX to the saline) in PCs were small and always subthreshold for spike initiation (Fig. 5C).

\section{EPSCs in RGCs}

To characterize in more detail the distinguishing properties of excitatory synaptic inputs to RGCs, we recorded under voltage clamp the EPSCs in 23 RGCs and 23 PCs in 38 different slices. In all these experiments, $10 \mu \mathrm{M}$ bicuculline was added to the salines to block $\mathrm{GABA}_{\mathrm{A}}$-ergic synaptic currents.

Representative recordings of EPSCs in the two types of neurons are shown in Figure 6. The stimulating electrode was positioned in the stratum radiatum, and the recordings at a holding potential of $-60 \mathrm{mV}$ were obtained from a PC (Fig. $6 A$ ) and from a nearby RGC (Fig. $6 B$ ). The position of the stimulating electrode was not changed, and the distance of the two cells from the electrode was identical (Dingledine et al., 1987). Nonetheless, stimulating the same afferent fibers evoked much larger EPSCs in RGCs than in PCs at all stimulus intensities (Fig. 6 $A, B$ ). Similar results were obtained in all pairs of PCs and RGCs $(n=8)$, even though the order of recording from the two cell types alternated. Thus, at maximal stimulus intensity $(50 \mathrm{~V})$ the EPSC amplitude ranged between 1 and $8 \mathrm{nA}$ in RGCs and between 0.2 and $2.7 \mathrm{nA}$ in PCs. As summarized in Figure $6 C$, the mean EPSC amplitudes were significantly larger in RGCs than in PCs at each stimulus
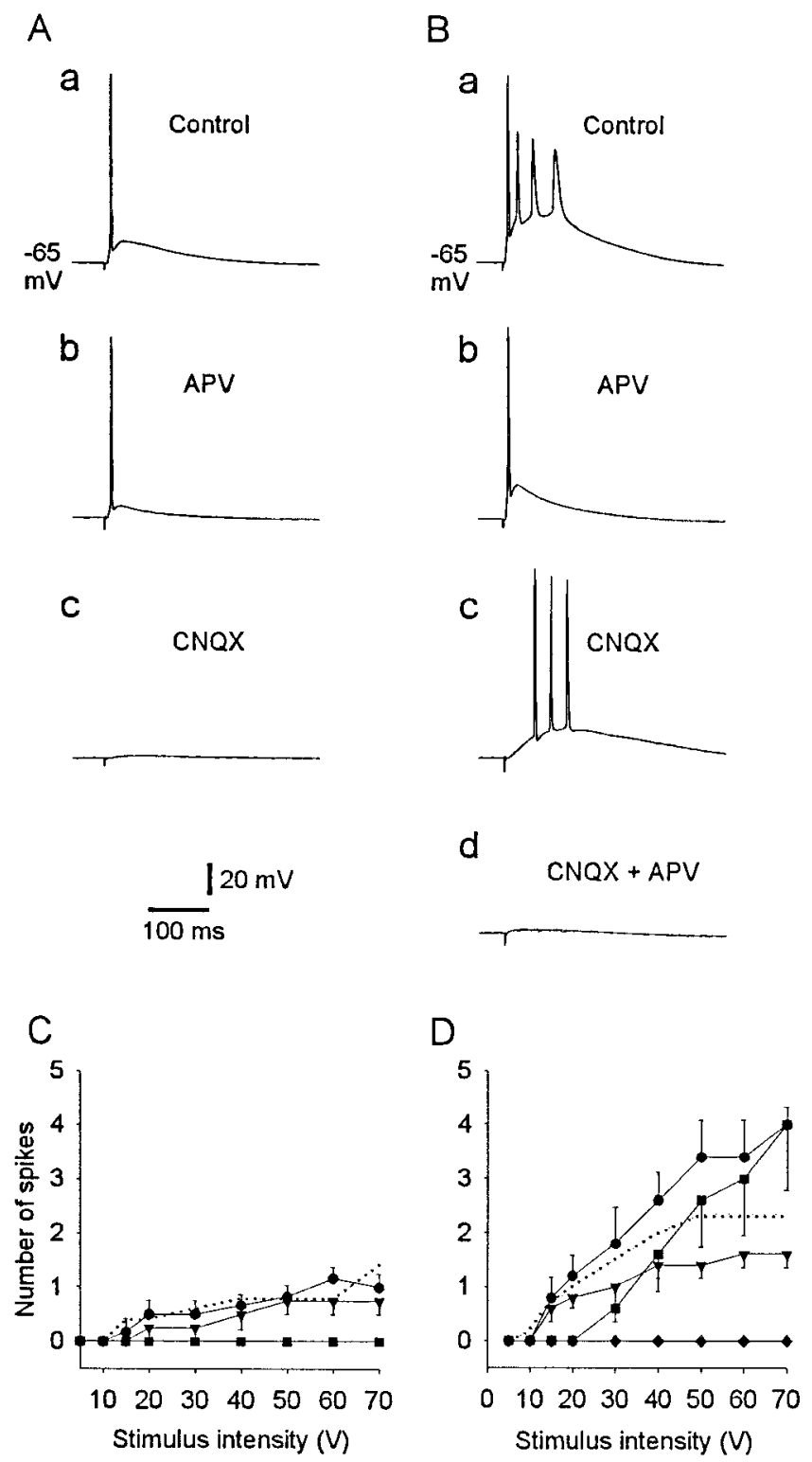

Figure 5. Effects of NMDA and non-NMDA receptor antagonists on synaptic activation of PCs versus RGCs. Current-clamp recordings were obtained in a PC $(A)$ and an RGC $(B)$ in slices perfused with saline containing $10 \mu \mathrm{M}$ bicuculline. The traces show the responses of the neurons to maximal orthodromic stimulation $(60 \mathrm{~V})$. In control conditions, the PC generated a single spike $(A, a)$, whereas the RGC fired a spike burst $(B, a)$. Adding $100 \mu \mathrm{M}$ APV to the salines did not affect the discharge of the PC, although it reduced its underlying $\operatorname{EPSP}(A, b)$. In the RGC, APV suppressed the burst discharge without affecting the early spike $(B, b)$. Adding $15 \mu \mathrm{M} C N Q X$ to the salines (after washing out APV; data not shown) suppressed the discharge of the $\mathrm{PC}(A, c)$ and the early spike in the response of the $\operatorname{RGC}(B, c)$. The $\operatorname{RGC}$ was completely silenced by adding APV to the CNQX-containing saline $(B, d)$. $C$, Graphs of the mean $\pm \mathrm{SE}$ number of spikes (input-output relations) generated in PCs $(n=5)$ versus stimulus intensity in bicuculline-containing saline (circles), after adding APV (inverted triangles) and after washing out APV and adding CNQX (squares). The dotted line represents the input-output relation of these neurons in standard saline. $D$, Same as in $C$, but for RGCs $(n=5)$. Shown in addition is the input-output relation in saline containing both CNQX and APV (diamonds). Error bars are one-sided for clarity. Note in $C$ and $D$ that adding APV did not affect the inputoutput relation of the PCs but reduced the output of the RGCs even below the values obtained in standard saline (dotted line). Adding CNQX completely suppressed the output of the PCs and shifted the input-output relation in the RGCs to the right. 
A

B
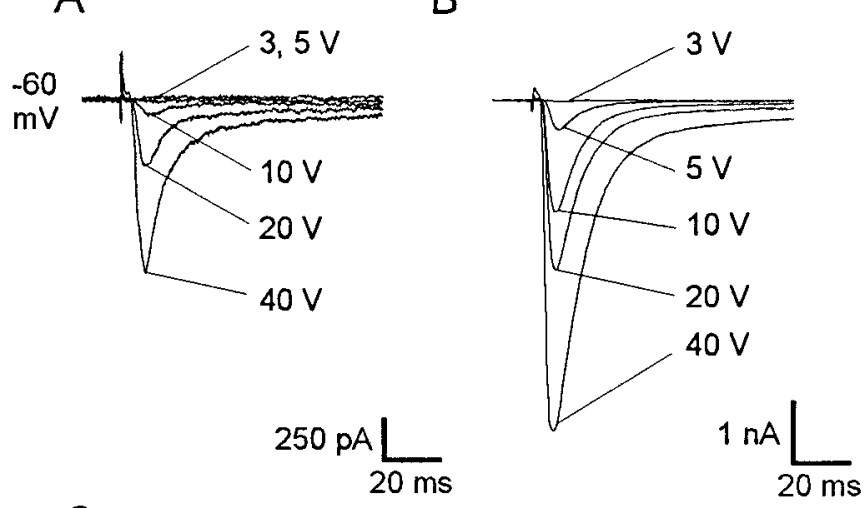

C

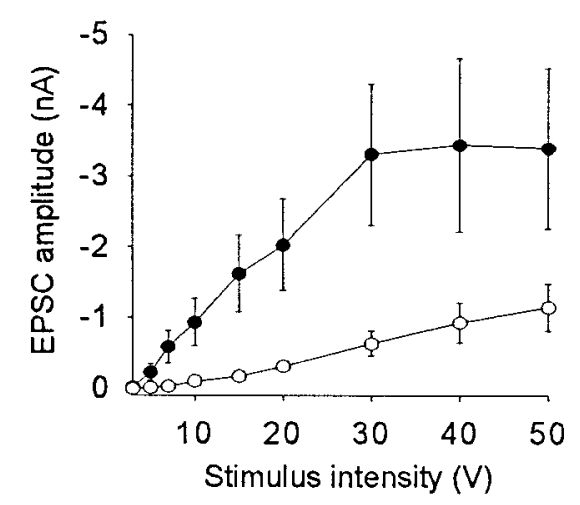

Figure 6. Orthodromic stimulation of the same afferent fibers evokes larger compound EPSCs in RGCs than in PCs. $A, B$, Voltage-clamp recordings of EPSCs in a PC $(A)$ and an RGC $(B)$ in a slice perfused with saline containing $10 \mu \mathrm{M}$ bicuculline. Both cells were clamped to $-60 \mathrm{mV}$. The position of the stimulating electrode was unchanged while recordings were obtained, first from the RGC and then from a nearby PC. In each panel, the superpositioned traces are the recordings of EPSCs evoked at different stimulus intensities, as indicated. Note the difference in the current calibration bars. $C$, Graphs of the mean \pm SE EPSC amplitude versus stimulus intensity in eight pairs of neighboring PCs (open circles) and RGCs (closed circles).

intensity $(-3.4 \pm 1.1 \mathrm{vs}-1.14 \pm 0.33 \mathrm{nA}$, respectively, at $50 \mathrm{~V})$. These data suggest that Schaffer collaterals and commissural fibers more strongly excite RGCs than PCs. This can be attributable to differences in the density and location of excitatory synaptic inputs and/or in the properties of individual synapses.

\section{Pharmacological isolation of two EPSC components}

The experiments described above have shown that both nonNMDA and NMDA receptors play a role in synaptic excitation of RGCs. We used APV and CNQX to pharmacologically isolate, respectively, the non-NMDA and NMDA EPSC components.

Figure 7 shows characteristic EPSCs recorded at $-60 \mathrm{mV}$ from a PC (Fig. 7A) and an RGC (Fig. 7B). Adding APV (100 $\mu \mathrm{M})$ inhibited the peak of the compound EPSC in the PC and the RGC by 8.5 and $35 \%$, respectively (Fig. $7 A, B$, compare $a, b$ ). Thus, NMDA receptors contribute appreciably to the generation of the early EPSC component in the RGC but only little in the PC. In both cells the late EPSC component was completely suppressed by APV (Fig. 7 $A, B$, compare $a, b$ ), indicating that in both cases it is generated solely by NMDA receptors. Consistent with these observations, adding CNQX $(15 \mu \mathrm{M})$ to the salines (after washing out APV; results not shown) isolated a large NMDA EPSC component in the RGC (Fig. $7 B, c$ ) but only a small such component in the $\mathrm{PC}$ (Fig. $7 A, c$ ). In both cases, exchanging to nominally $\mathrm{Mg}^{2+}$-free saline greatly enhanced the NMDA EPSC (Fig. 7 $A, B$, compare $c, d$ ), but this effect was much more pronounced in the PC (a 10-fold increase) than in the RGC (a 2-fold increase).

Similar observations were made in $11 \mathrm{PCs}(9.3 \pm 1.2$-fold increase) and 12 RGCs (3.5 \pm 0.6 -fold increase), suggesting that synaptic NMDA receptors in RGCs are significantly less sensitive to blockade by $\mathrm{Mg}^{2+}$ than in PCs $(p=0.002)$.

\section{Current-voltage relation of non-NMDA EPSCs}

Typical pharmacologically isolated non-NMDA EPSCs evoked at different holding potentials in a $\mathrm{PC}$ and in an $\mathrm{RGC}$ are illustrated in Figure 8. In both the PC (Fig. $8 A, a, b$ ) and the RGC (Fig. $8 B, a, b$ ), the non-NMDA EPSCs reversed at $\sim 0 \mathrm{mV}$ and had a nearly linear $I-V$ relation. The $I-V$ relations from six PCs and nine RGCs were normalized to their maximal inward current and averaged for comparison (Fig. 8C). No significant differences were found between the $I-V$ relations in the two cell types.

\section{Current-voltage relation of NMDA EPSCs}

Typical pharmacologically isolated NMDA EPSCs evoked at different holding potentials in a PC and in an RGC are illustrated in Figure 9. In both the PC (Fig. 9A, $a, b$ ) and the RGC (Fig. 9B, $a, b)$, the NMDA EPSCs reversed at $\sim 4 \mathrm{mV}$ and exhibited a region of negative slope conductance in the $I-V$ relation at negative holding potentials. However, this region started at a membrane potential $20 \mathrm{mV}$ more negative in the $\mathrm{RGC}(-48 \mathrm{mV})$ than in the PC $(-28 \mathrm{mV})$. In Figure $9 C$, the averaged normalized $I-V$ relations of NMDA EPSCs in 8 PCs and 11 RGCs were superimposed for comparison. In both cases the EPSCs reversed at the same membrane potential (1.7 $\mathrm{mV}$ in PCs and $2.3 \mathrm{mV}$ in RGCs), but the region of negative slope conductance in the $I-V$ relation started $12 \mathrm{mV}$ more negative in the RGCs $(-39 \mathrm{mV})$ than in the PCs $(-27 \mathrm{mV})$. Consequently, NMDA EPSCs evoked at a voltage approximating resting membrane potential $(-60 \mathrm{mV})$ were less inhibited in RGCs ( $35 \pm 3 \%$ of maximal current) than in PCs (55 $\pm 7 \%$ of maximal current).

To quantify these differences more accurately, the apparent $K_{\mathrm{d}}$ of $\mathrm{Mg}^{2+}$ from NMDA receptors in PCs and RGCs was deduced from functions 2 and 3 (see Materials and Methods). We found that the affinity of NMDA receptors for $\mathrm{Mg}^{2+}$ at resting membrane potential (approximately $-60 \mathrm{mV}$ ) was significantly higher in PCs than in RGCs $\left(K_{\mathrm{d}(-60 \mathrm{mV})}, 0.15 \pm 0.05\right.$ vs. $0.42 \pm 0.07 \mathrm{~mm}$, respectively). The results in the PCs are almost identical to those we found in a previous study of adult CA1 PCs, where the $K_{\mathrm{d}}$ was calculated directly from dose-response relations of NMDA receptor-mediated current blockade by several different $\mathrm{Mg}^{2+}$ concentrations $\left(K_{\mathrm{d}(-60 \mathrm{mv})}, 0.13 \pm 0.03 \mathrm{~mm}\right.$; Kirson et al., 1999). To estimate the fraction of the electrical field felt by the blocking $\mathrm{Mg}^{2+}$ ions $(\delta)$, we also fitted the $I-V$ relations with the Woodhull equation (Eq. 4; see Materials and Methods). We found that in RGCs, the $\mathrm{Mg}^{2+}$ block of NMDA receptors is less voltagedependent than in PCs ( $\delta=0.80$ vs 0.95 , respectively). The $\delta$ value obtained for PCs is very similar to that which we reported previously for adult CA1 PCs ( $\delta=0.99$; Kirson et al., 1999).

\section{Kinetics of isolated NMDA EPSCs}

In central neurons, NMDA EPSCs have a relatively long time course (up to several seconds), but their precise kinetics may vary among different cell types even in the same structure (Keller et al., 1991; Perouansky and Yaari, 1993; Spruston et al., 1995). In 
Figure 7. Augmented contribution of NMDA receptors to the compound EPSC in RGC versus PC. $A, B$, Voltage-clamp recordings of EPSCs in a PC $(A)$ and an RGC $(B)$ in slices perfused with saline containing $10 \mu \mathrm{M}$ bicuculline. Both cells were clamped to -60 $\mathrm{mV}$. The intensities of the orthodromic stimuli were 15 and $10 \mathrm{~V}$ for the PC and RGC, respectively. Note the difference in the current calibration bars. Despite the stronger stimulation of the PC, the compound EPSC evoked in this neuron $(A, a)$ was much smaller than that evoked in the RGC $(B, a)$. Adding $100 \mu \mathrm{M}$ APV to the saline reversibly reduced the peak of the EPSC in the PC $(A, b)$ and in the RGC $(B, b)$ by 8.5 and $35 \%$, respectively. It also completely suppressed the late EPSC component in both cells $(A, B, b)$. Adding $15 \mu \mathrm{M}$ CNQX to the saline exposed a larger NMDA EPSC component in the $\operatorname{RGC}(B, c)$ than in the PC $(A, c)$. Deleting the $\mathrm{Mg}^{2+}$ from the CNQX-containing saline caused an increase in the size of the NMDA EPSC component, which was more pronounced in the PC (10-fold; $A, d$ ) than in the RGC (2-fold; $B, d$ ).
A

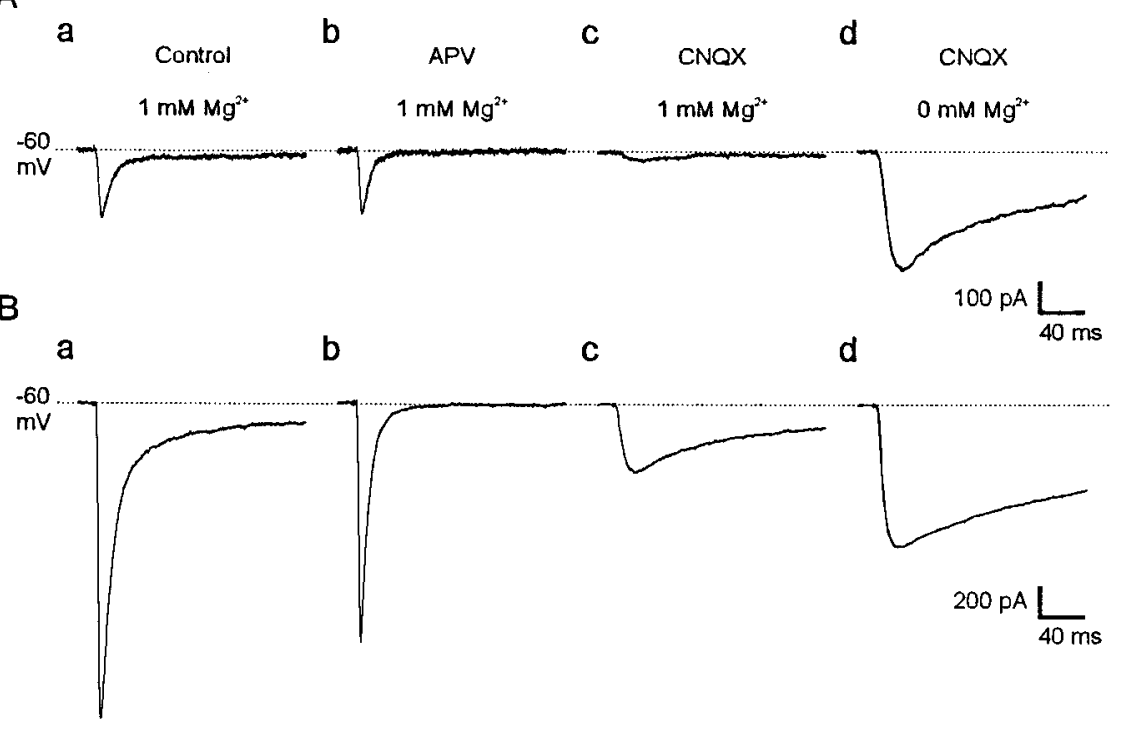

light of this heterogeneity, we compared the time course of NMDA EPSCs in PCs versus RGCs. Representative NMDA EPSCs evoked at $-60 \mathrm{mV}$ in $\mathrm{Mg}^{2+}$-free saline in a $\mathrm{PC}$ and an RGC are shown, respectively, in Figure $10, A$ and $B$. They are superimposed after scaling in Figure $10, C$ and $D$. It can be seen in these examples that the EPSC rise time was faster in the RGC than in the PC (9.6 vs $12 \mathrm{msec}$, respectively; Fig. 10C). As previously shown in CA1 PCs (Perouansky and Yaari, 1993; Kirson and Yaari, 1996), the EPSC decay in both cell types was described accurately by the sum of two exponential functions (see Materials and Methods). The EPSC decay was much slower in the RGC than in the PC, even though the overall duration of the EPSCs was the same in both cells $(\sim 2.8 \mathrm{sec}$; Fig. $10 \mathrm{D})$. Analysis of the NMDA EPSC decay waveform indicated that the relative contribution of $A_{\mathrm{f}}$ compared with $A_{\mathrm{s}}$ was much smaller in the $\operatorname{RGC}\left(A_{\mathrm{f}} / A_{\mathrm{s}}=2.25\right)$ than in the PC $\left(A_{\mathrm{f}} / A_{\mathrm{s}}=6.2\right)$, but the decay time constants were similar in both cells.

Results obtained in similar conditions from 10 RGCs and 10 $\mathrm{PCs}$ are shown after averaging in Figure $10 E-G$. The rise times of NMDA EPSCs were significantly faster in RGCs than in PCs $(9.6 \pm 0.7 \mathrm{msec}$ in RGCs vs $11.7 \pm 0.6 \mathrm{msec}$ in PCs; Fig. 10E). The NMDA EPSC decays were much slower in RGCs than in PCs. This was attributable to a significantly smaller contribution of $A_{\mathrm{f}}$ compared with $A_{\mathrm{s}}$ to the EPSC decay $\left(A_{\mathrm{f}} / A_{\mathrm{s}}=2.5 \pm 0.3\right.$ in RGCs vs $4.5 \pm 0.7$ in PCs; Fig. $10 F)$. No significant differences were found in either fast $\left(\tau_{\mathrm{f}}\right)$ or slow $\left(\tau_{\mathrm{s}}\right)$ decay time constants between RGCs and PCs $\left(\tau_{\mathrm{f}}=124 \pm 39 \mathrm{msec}\right.$ in RGCs vs $96 \pm$ $18 \mathrm{msec}$ in PCs; $\tau_{\mathrm{s}}=852 \pm 67 \mathrm{msec}$ in RGCs vs $878 \pm 76 \mathrm{msec}$ in PCs; Fig. 10G).

\section{Evaluation of space-clamp errors}

Even though we stimulated afferent fibers near $(\sim 200 \mu \mathrm{m})$ the soma of the cells recorded from, it is possible that the complex dendritic geometry of PCs and RGCs will impose imperfect space-clamp conditions, thereby distorting the waveform of the NMDA EPSCs. We have previously shown that NMDA EPSCs in adult PCs are not subjected to such distortion (Hestrin et al., 1990; Kirson and Yaari, 1996). We used the same procedures to assess voltage-clamp errors in the kinetics of NMDA EPSCs in RGCs. First, we looked at whether holding the neuron at the NMDA EPSC reversal potential would affect its subsequent de-
A

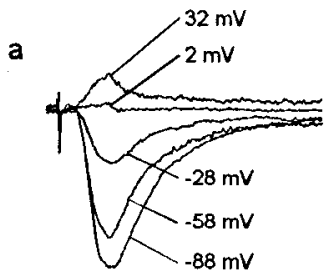

B
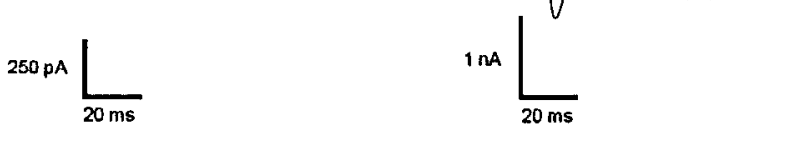

b
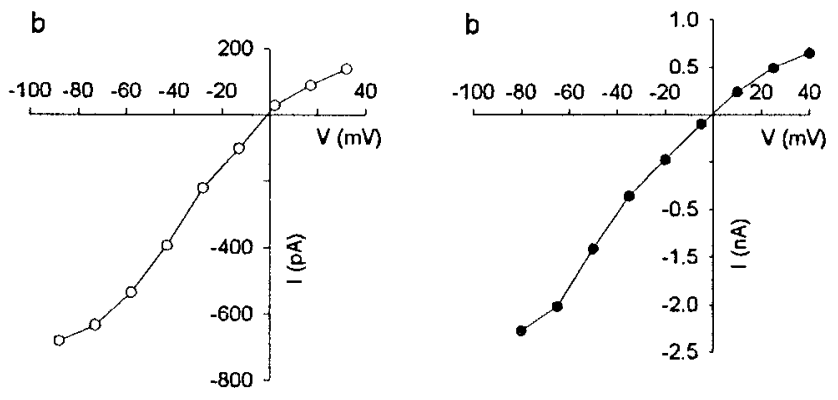

C

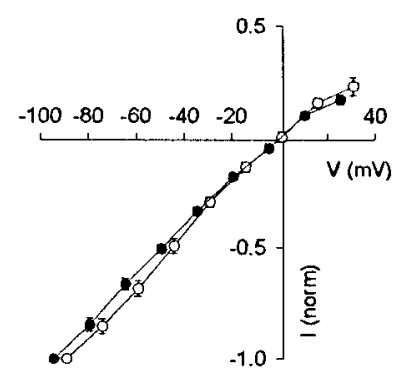

Figure 8. The $I-V$ relations of non-NMDA EPSCs in RGCs and PCs are identical. $A, B$, Voltage-clamp recordings of pharmacologically isolated non-NMDA EPSCs in a PC $(A)$ and an RGC $(B)$ in slices perfused with saline containing $10 \mu \mathrm{M}$ bicuculline and $100 \mu \mathrm{M}$ APV. $a$, Superpositioned recordings of the non-NMDA EPSCs evoked at different holding potentials, as indicated. $b$, Respective $I-V$ relations of the EPSCs shown in $a$. $C$, Averaged $I-V$ relations obtained from six PCs (open circles) and nine RGCs (closed circles) after normalization to the maximal inward current. 
A

a

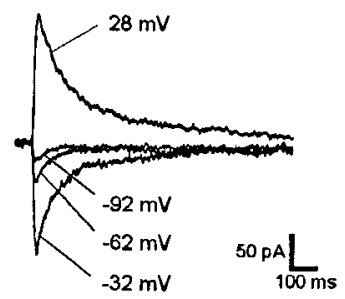

B

a

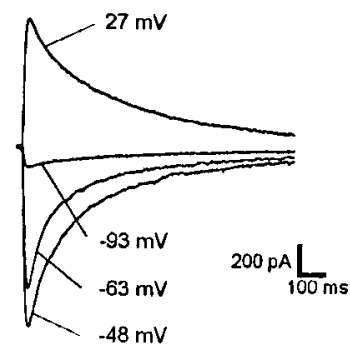

b

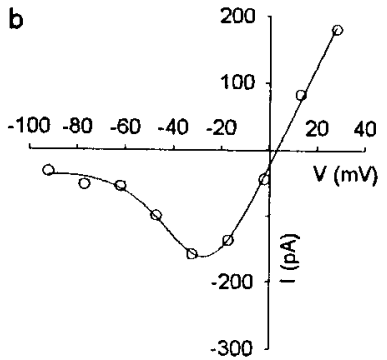

b

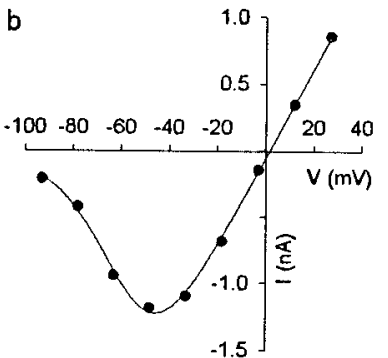

C

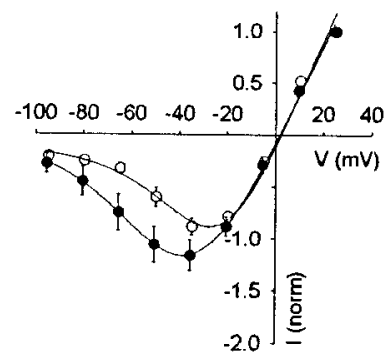

Figure 9. The $I-V$ relations of NMDA EPSCs are less sensitive to negative membrane potentials in RGCs than in PCs. $A, B$, Voltage-clamp recordings of pharmacologically isolated NMDA EPSCs in a $\mathrm{PC}(A)$ and an RGC $(B)$ in slices perfused with saline containing $10 \mu \mathrm{M}$ bicuculline and $15 \mu \mathrm{M}$ CNQX. The $\mathrm{Mg}^{2+}$ concentration of the saline was $1 \mathrm{~mm} . a$, Superpositioned recordings of the NMDA EPSCs evoked at different holding potentials, as indicated. $b$, Respective $I-V$ relations of the EPSCs shown in $a$. $C$, Averaged $I-V$ relations obtained from 8 PCs (open circles) and 11 RGCs (closed circles) after normalization to the maximal outward current. Note that the region of negative slope conductance in the $I-V$ relation begins at a more negative voltage in the RGC than in the PC.

cay. The experimental paradigm and representative results are illustrated in Figure 11. Synaptic stimulation was delivered while membrane potential was held at the NMDA EPSC reversal potential $(\sim 0 \mathrm{mV})$, so that no net current was flowing through the synaptic conductance. In sequential repetitions of this paradigm, the membrane potential was stepped to $-60 \mathrm{mV}$ at increasing intervals (200, 400, 600, 800, and $1000 \mathrm{msec}$ ) after stimulation. Responses to the same voltage commands without synaptic stimulation were subtracted from the NMDA EPSC recordings. The decays of the residual NMDA EPSCs appearing at $-60 \mathrm{mV}$ reflect the deactivation time course of the synaptic conductance (Pearce, 1993). These decays matched exactly the decay of the NMDA EPSC evoked at $-60 \mathrm{mV}$ (Fig. 11), indicating that the latter is not distorted by dendritic filtering. Similar results were obtained in five RGCs.

Second, we tested for correlations in RGCs between NMDA
A

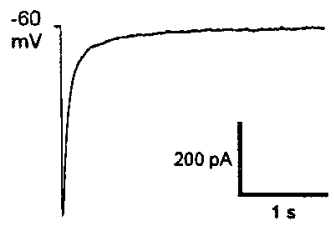

C

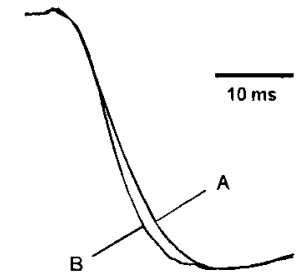

D
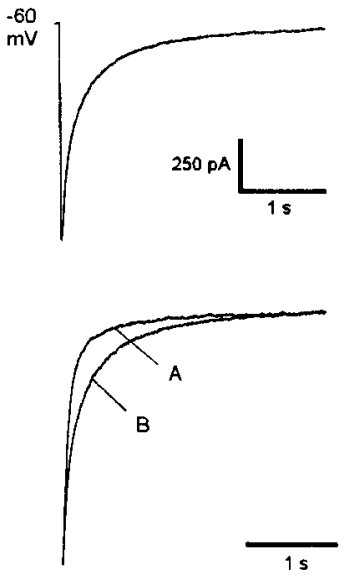

E F
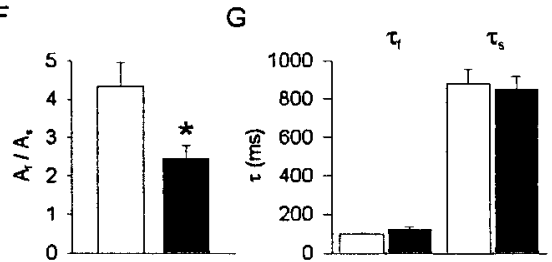

Figure 10. The NMDA EPSCs in RGCs have distinguishing kinetic properties. $A, B$, Voltage-clamp recordings of pharmacologically isolated NMDA EPSCs at a holding potential of $-60 \mathrm{mV}$ in a PC $(A)$ and an RGC $(B)$ in slices perfused with nominally $\mathrm{Mg}^{2+}$-free saline containing $10 \mu \mathrm{M}$ bicuculline and $15 \mu \mathrm{M}$ CNQX. $C$, Portions of the traces in $A$ and $B$ comprising the rise times of the EPSCs shown superpositioned on an expanded time scale after scaling to the same peak current. $D$, Portions of the traces in $A$ and $B$ comprising the decay component of the EPSCs shown superpositioned after scaling to the same peak current. $E-G$, Bar charts of the mean kinetic parameters of NMDA EPSCs obtained from 9 PCs (open bars) and 10 RGCs (closed bars). E, Ten to 90\% EPSC rise times. $F$, Ratio of the amplitudes of the fast and the slowly decaying EPSC components $\left(A_{\mathrm{f}} / A_{\mathrm{s}}\right)$. Significant differences are indicated by an asterisk. See Results for more details.

EPSC rise times and decay time constants $\left(r^{2}=0.16\right.$ and 0.17 for $\tau_{\mathrm{f}}$ and $\tau_{\mathrm{s}}$, respectively; Pearson linear correlation) and between NMDA EPSC amplitudes and decay time constants $\left(r^{2}=0.09\right.$ and 0.06 for $\tau_{\mathrm{f}}$ and $\tau_{\mathrm{s}}$, respectively; Pearson linear correlation). If the NMDA EPSC decay kinetics were affected by dendritic filtering, then significant positive correlations between these variables would be expected (Spruston et al., 1993). However, no such correlations were found. Taken together, these data do not indicate a significant distortion of NMDA EPSC waveform by voltage-clamp errors.

Finally, it could be argued that the lower $\mathrm{Mg}^{2+}$ sensitivity of synaptic NMDA receptors in RGCs compared with PCs is the result of compromised voltage-clamp conditions. An important factor determining the effectiveness of voltage-clamp conditions is the electrotonic distance of the synapses from the recording site. Less efficient voltage clamp in RGCs, as a result of recording from more electrotonically distant synapses compared with PCs, would be expected to slow the kinetics of fast synaptic events. However, we found that the rise times of non-NMDA EPSC were significantly faster in RGCs than in PCs $(2.5 \pm 0.2$ vs $3.3 \pm 0.15$ msec, respectively). Therefore, we conclude that the differential $\mathrm{Mg}^{2+}$ sensitivity of synaptic NMDA receptors in RGCs compared with PCs reflects unique properties of the NMDA receptors themselves. 

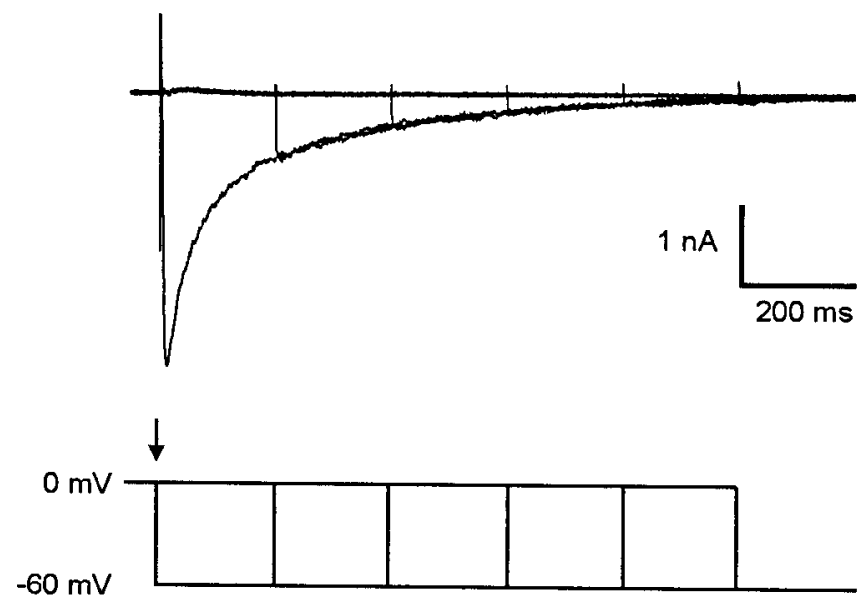

Figure 11. Evaluation of the efficacy of space clamping and the true decay of the synaptic conductance of NMDA EPSCs in RGCs. The bottom traces describe the waveform of the voltage steps. Each trial began by holding the cell membrane potential at $0 \mathrm{mV}$ (the approximate NMDA EPSC reversal potential) for several seconds (to allow for inactivation of voltage-activated currents), after which the EPSC was evoked at the time indicated by the arrow. In six consecutive trials, the membrane potential was maintained at $0 \mathrm{mV}$ for increasingly longer durations after stimulation $(0,200,400,600,800$, and $1000 \mathrm{msec})$ and then was stepped to -60 $\mathrm{mV}$. Similar trials were repeated also without synaptic stimulation. The top traces depict the EPSCs evoked in each trial after subtraction of the corresponding responses obtained without synaptic stimulation. No synaptic current was seen at $0 \mathrm{mV}$. Stepping back to $-60 \mathrm{mV}$ induced a current that decayed along a similar time course in all trials. This indicates that the EPSC decay is attributable solely to decay of the synaptic conductance.

\section{DISCUSSION}

In the present study we have characterized synaptic excitation in a newly described type of hippocampal projection neuron, the RGC. We found that although RGCs are similar to PCs in their intrinsic features, their recruitment by synaptic stimulation differs significantly. Whereas afferent fiber stimulation evokes maximally one action potential in PCs, the same stimulation readily evokes a spike burst in RGCs. Furthermore, the burst response persists after blockade of non-NMDA receptors but is sensitive to blocking NMDA receptors, indicating an enhanced NMDA EPSC component in these neurons. Our data suggest that this is attributable to unique properties of synaptic NMDA receptors in RGCs.

\section{Intrinsic versus synaptic factors}

We found that whereas PCs fire only a single spike in response to synaptic activation, RGCs can fire a burst of several action potentials. The enhanced responses in RGCs could be due to intrinsic factors, i.e., RGCs may be triggered by normal EPSPs to fire bursts of action potentials because of the activation of slow voltage-gated inward currents. Conversely, RGCs may be less inhibited synaptically or may possess more efficient excitatory synapses. In agreement with previous studies (Maccaferri and McBain, 1996; Gulyas et al., 1998), we found that both RGCs and PCs are regular firing cells in standard saline and do not differ with respect to other passive or active membrane properties. Therefore, the enhanced synaptic excitation of RGCs is not attributable to an inherent propensity to fire bursts of action potentials.

The enhanced synaptic excitation of RGCs versus PCs is not the result of less efficient feedforward and/or feedback inhibition of the former neurons, because the differences in excitability between the two cell types persisted, and even were augmented, after disinhibition with bicuculline. Taken together, these data suggest that RGCs have more efficient excitatory synapses than PCs.

\section{Synaptic excitation of RGCs}

Even when activated by the same population of afferent fibers, the amplitude of the compound EPSCs was at least threefold greater in RGCs than in PCs at all stimulus intensities. This difference could be attributable to an interplay of several factors. First, the Schaffer collateral and commissural fibers may form more excitatory synaptic contacts with RGCs than with PCs. Second, the excitatory synapses may be electrotonically closer to the soma in RGCs than in PCs. Third, the properties of individual synapses may differ between the cell types. Our study bears on only one aspect of the latter factor, namely, the contribution of synaptic NMDA receptors to the enhanced excitation of RGCs.

As shown previously (Koerner and Cotman, 1982; Collingridge et al., 1983; Neuman et al., 1988; Andreasen et al., 1989), we found that synaptic excitation of CA1 PCs is predominantly a non-NMDA receptor-dependent process and that NMDA receptors contribute minimally to low-frequency synaptic transmission in these cells (Collingridge et al., 1983; Hestrin et al., 1990; Sah et al., 1990; Keller et al., 1991; Perouansky and Yaari, 1993). In contrast, we found that NMDA receptors markedly enhance the responses of RGCs to the stimulation of excitatory afferents, leading to a burst of several spikes after the primary action potential. The activation of synaptic NMDA receptors did not require postsynaptic depolarization by coactivated non-NMDA receptors, as is the case of CA1 PCs (Herron et al., 1986). Rather large EPSPs could be evoked in RGCs even after blockage of non-NMDA receptors, indicating that a substantial fraction of these receptors are not blocked at resting membrane potential.

\section{Distinguishing properties of NMDA EPSCs in RGCs}

The non-NMDA EPSCs recorded in RGCs were similar to those recorded in PCs. The reversal potential of these EPSCs and the linearity of their $I-V$ relations were identical. Our data are similar to results obtained in previous studies of non-NMDA EPSCs in hippocampal PCs and granule cells (Hestrin et al., 1990; Keller et al., 1991). We made no attempt to compare the kinetics of isolated non-NMDA EPSCs, because of the known limitations of somatic whole-cell patch-clamp recording of fast events initiated in complex dendritic structures (Spruston et al., 1994).

The NMDA EPSCs recorded in RGCs differed substantially from those recorded in PCs. As described previously for other cell types (Mayer et al., 1984; Nowak et al., 1984; Ascher and Nowak, 1988), NMDA receptors in RGCs were blocked by $\mathrm{Mg}^{2+}$ at resting membrane potential. However, the magnitude of blockage was much smaller than in the PCs. This was apparent in the $I-V$ relations of NMDA EPSCs in RGCs, which exhibited an area of negative slope conductance that was shifted by $12 \mathrm{mV}$ to more hyperpolarized potentials compared with that in PCs. This is attributable to the lower affinity for $\mathrm{Mg}^{2+}$ (higher $K_{\mathrm{d}}$ ) of NMDA receptors at resting membrane potential in RGCs than in PCs. Consequently, even in normal extracellular $\mathrm{Mg}^{2+}$ concentration, a substantial NMDA receptor-mediated EPSP component was present at resting membrane potential in the RGCs.

We also found that NMDA EPSCs in RGCs have faster rise times and slower decay kinetics than in PCs. The faster rise times may be attributable to differences in the gating properties of individual NMDA receptors. Conversely, they may be a reflection of synapses located electrotonically closer to the soma in RGCs 
than in PCs. In either case, the faster rise times would allow NMDA receptors to participate more effectively in the initial phase of the EPSP.

Analysis of the biexponential decay kinetics of NMDA EPSCs in PCs and RGCs indicated no differences in the time constants of decay $\left(\tau_{\mathrm{f}}\right.$ and $\tau_{\mathrm{s}}$ ) between the two cell types. Rather, the slower decay in RGCs was the result of a relatively larger slow component $\left(A_{\mathrm{s}}\right)$ of decay. The slower decay kinetics of NMDA receptors in RGCs, by causing a greater charge transfer through the receptor channels, would contribute to the sustained synaptic activation of these neurons. It also would lead to an increased calcium signal in these neurons, which may be important for their ability to express LTP (Maccaferri and McBain, 1996).

\section{Implications for subunit composition of NMDA receptors in RGCs}

Native NMDA receptors are believed to be multimeric proteins assembled from several subunits. In the rat, these include the NR1, NR2A-D, and NR3A subunits (for review, see Mori and Mishina, 1995). It is thought that some of the properties of these receptors are determined by the type of NR2 subunit incorporated. Indeed, recombinant heterodimeric NMDA receptors containing the NR2A or NR2B subunits are more strongly blocked by $\mathrm{Mg}^{2+}$ than those containing the NR2C or NR2D subunits (Monyer et al., 1994; Kuner and Schoepfer, 1996). Also, recombinant receptors containing the NR2A subunit have the fastest offset kinetics ( $\sim 100 \mathrm{msec})$, those containing the NR2B or NR2C subunits have intermediate offset kinetics $(\sim 400 \mathrm{msec})$, and those containing the NR2D subunit have the slowest offset kinetics (seconds; Monyer et al., 1992, 1994; Wyllie et al., 1998). Accordingly, it has been argued that developmental changes in the $\mathrm{Mg}^{2+}$ sensitivity and time course of NMDA EPSCs in central neurons may involve down-regulation of the NR2B and NR2D subunits and concurrent up-regulation of the NR2A subunit (Kirson and Yaari, 1996; Takahashi et al., 1996; Flint et al., 1997; Kirson et al., 1999).

The differences in the $\mathrm{Mg}^{2+}$ sensitivity and time course of NMDA EPSCs between PCs and RGCs described here also may reflect differences in the subunit composition of the respective NMDA receptors. Several studies have shown that adult CA1 PCs express only the NR2A and NR2B subunits (Monyer et al., 1994; Kirson et al., 1999), which would impart a high $\mathrm{Mg}^{2+}$ sensitivity and relatively fast kinetics to their NMDA EPSCs. The lower $\mathrm{Mg}^{2+}$ sensitivity and longer EPSC kinetics of NMDA receptors in RGCs suggest the contribution of other NR2 subunits to the synaptic NMDA receptors in these neurons. A likely candidate would be the NR2D subunit, given its low $\mathrm{Mg}^{2+}$ sensitivity and slow offset kinetics (Monyer et al., 1994).

\section{Concluding remarks}

Three factors were found to contribute to the enhanced synaptic excitability of RGCs versus PCs, namely, much larger EPSCs, decreased blockade of synaptic NMDA receptors by $\mathrm{Mg}^{2+}$, and prolonged decay of NMDA EPSCs. In adult mammalian central neurons, glutamatergic synaptic excitation mediated predominantly by NMDA receptors has been demonstrated previously in the cat spinal cord (Davies and Watkins, 1983) and visual cortex (Fox et al., 1989, 1990) and in the mouse barrel cortex (Fleidervish et al., 1998). In the latter case this was attributed to functionally distinct NMDA receptors having a lower sensitivity to $\mathrm{Mg}^{2+}$ blockage. However, RGCs are the first hippocampal neurons shown to manifest this exceptional form of synaptic recruitment.
The precise role of RGCs in the hippocampal network is yet unknown. Given their enhanced NMDA receptor-dependent synaptic excitability, they may serve to amplify specific output signals of the hippocampus. Because their axons ramify also locally (Gulyas et al., 1998), RGCs may serve an important role in information processing within the hippocampus. However, identification of their extrahippocampal and intrahippocampal target cells, as well as their precise afferent innervation, would be required before assessing their exact functions in neuronal integration within the limbic system.

\section{REFERENCES}

Amaral DG, Woodward DJ (1977) A hippocampal interneuron observed in the inferior region. Brain Res 124:225-236.

Andreasen M, Lambert JD, Jensen MS (1989) Effects of new non- $N$ methyl-D-aspartate antagonists on synaptic transmission in the in vitro rat hippocampus. J Physiol (Lond) 414:317-336.

Ascher P, Nowak L (1988) The role of divalent cations in the $N$-methylD-aspartate responses of mouse central neurones in culture. J Physiol (Lond) 399:247-266.

Bliss TV, Collingridge GL (1993) A synaptic model of memory: longterm potentiation in the hippocampus. Nature 361:31-39.

Collingridge GL, Kehl SJ, McLennan H (1983) Excitatory amino acids in synaptic transmission in the Schaffer collateral-commissural pathway of the rat hippocampus. J Physiol (Lond) 334:33-46.

Davies J, Watkins JC (1983) Role of excitatory amino acid receptors in mono- and polysynaptic excitation in the cat spinal cord. Exp Brain Res 49:280-290.

Dingledine R, Roth AA, King GL (1987) Synaptic control of pyramidal cell activation in the hippocampal slice preparation in the rat. Neuroscience 22:553-561.

Edwards FA, Konnerth A, Sakmann B, Takahashi T (1989) A thin slice preparation for patch clamp recordings from neurones of the mammalian central nervous system. Pflügers Arch 414:600-612.

Fleidervish IA, Binshtok AM, Gutnick MJ (1998) Functionally distinct NMDA receptors mediate horizontal connectivity within layer 4 of mouse barrel cortex. Neuron 21:1055-1065.

Flint AC, Maisch US, Weishaupt JH, Kriegstein AR, Monyer H (1997) NR2A subunit expression shortens NMDA receptor synaptic currents in developing neocortex. J Neurosci 17:2469-2476.

Fox K, Sato H, Daw N (1989) The location and function of NMDA receptors in cat and kitten visual cortex. J Neurosci 9:2443-2454.

Fox K, Sato H, Daw N (1990) The effect of varying stimulus intensity on NMDA-receptor activity in cat visual cortex. J Neurophysiol 64:1413-1428.

Freund TF, Buzsaki G (1996) Interneurons of the hippocampus. Hippocampus $6: 347-470$.

Gulyas AI, Toth K, McBain CJ, Freund TF (1998) Stratum radiatum giant cells: a type of principal cell in the rat hippocampus. Eur J Neurosci 10:3813-3822.

Herron CE, Lester RAJ, Coan EJ, Collingridge GL (1986) Frequencydependent involvement of NMDA receptors in the hippocampus: a novel synaptic mechanism. Nature 322:265-268.

Hestrin S, Nicoll RA, Perkel DJ, Sah P (1990) Analysis of excitatory synaptic action in pyramidal cells using whole-cell recording from rat hippocampal slices. J Physiol (Lond) 422:203-225.

Jensen MS, Azouz R, Yaari Y (1996) Spike after-depolarization and burst generation in adult rat hippocampal CA1 pyramidal cells. J Physiol (Lond) 492:199-210.

Keller BU, Konnerth A, Yaari Y (1991) Patch clamp analysis of excitatory synaptic currents in granule cells of rat hippocampus. J Physiol (Lond) 435:275-293.

Kirson ED, Yaari Y (1996) Synaptic NMDA receptors in developing mouse hippocampal neurones: functional properties and sensitivity to ifenprodil. J Physiol (Lond) 497:437-455.

Kirson ED, Schirra C, Konnerth A, Yaari Y (1999) Early postnatal switch in the magnesium sensitivity of NMDA receptors in rat CA1 pyramidal cells. J Physiol (Lond) 521:99-111.

Koerner JF, Cotman CW (1982) Response of Schaffer collateral-CA1 pyramidal cell synapses of the hippocampus to analogues of acidic amino acids. Brain Res 251:105-115.

Kuner T, Schoepfer R (1996) Multiple structural elements determine 
subunit specificity of $\mathrm{Mg}^{2+}$ block in NMDA receptor channels. J Neurosci 16:3549-3558.

Lang U, Frotscher M (1990) Postnatal development of nonpyramidal neurons in the rat hippocampus (areas CA1 and CA3): a combined Golgi/electron microscope study. Anat Embryol (Berl) 181:533-545.

Maccaferri G, McBain CJ (1996) Long-term potentiation in distinct subtypes of hippocampal nonpyramidal neurons. J Neurosci 16:5334-5343.

Mayer ML, Westbrook GL, Guthrie PB (1984) Voltage-dependent block by $\mathrm{Mg}^{2+}$ of NMDA responses in spinal cord neurones. Nature 309:261-263.

Monyer H, Sprengel R, Schoepfer R, Herb A, Higuchi M, Lomeli H, Burnashev N, Sakmann B, Seeburg PH (1992) Heteromeric NMDA receptors: molecular and functional distinction of subtypes. Science 256:1217-1221.

Monyer H, Burnashev N, Laurie DJ, Sakmann B, Seeburg PH (1994) Developmental and regional expression in the rat brain and functional properties of four NMDA receptors. Neuron 12:529-540.

Mori H, Mishina M (1995) Structure and function of the NMDA receptor channel. Neuropharmacology 34:1219-1237.

Neuman RS, Ben Ari Y, Gho M, Cherubini E (1988) Blockade of excitatory synaptic transmission by 6-cyano-7-nitroquinoxaline-2,3dione (CNQX) in the hippocampus in vitro. Neurosci Lett 92:64-68.

Nowak L, Bregestovski P, Ascher P, Herbet A, Prochiantz A (1984) Magnesium gates glutamate-activated channels in mouse central neurones. Nature 307:462-465.

Pearce RA (1993) Physiological evidence for two distinct $\mathrm{GABA}_{\mathrm{A}}$ responses in rat hippocampus. Neuron 10:189-200.

Perouansky M, Yaari Y (1993) Kinetic properties of NMDA receptor- mediated synaptic currents in rat hippocampal pyramidal cells versus interneurones. J Physiol (Lond) 465:223-244.

Ramon y Cajal S (1968) The structure of Ammon's horn. Springfield, IL: Thomas.

Sah P, Hestrin S, Nicoll RA (1990) Properties of excitatory postsynaptic currents recorded in vitro from rat hippocampal interneurones. J Physiol (Lond) 430:605-616.

Spruston N, Jaffe DB, Williams SH, Johnston D (1993) Voltage- and space-clamp errors associated with the measurement of electrotonically remote synaptic events. J Neurophysiol 70:781-802.

Spruston N, Jaffe DB, Johnston D (1994) Dendritic attenuation of synaptic potentials and currents: the role of passive membrane properties. Trends Neurosci 17:161-166.

Spruston N, Jonas P, Sakmann B (1995) Dendritic glutamate receptor channels in rat hippocampal CA3 and CA1 pyramidal neurons. J Physiol (Lond) 482:325-352.

Takahashi T, Feldmeyer D, Suzuki N, Onodera K, Cull Candy SG, Sakimura K, Mishina M (1996) Functional correlation of NMDA receptor epsilon subunits expression with the properties of singlechannel and synaptic currents in the developing cerebellum. J Neurosci $16: 4376-4382$.

Traub RD, Miles R (1991) Neural networks of the hippocampus. Cambridge, UK: Cambridge UP.

Woodhull AM (1973) Ionic blockage of sodium channels in nerve. J Gen Physiol 61:687-708.

Wyllie DJ, Behe P, Colquhoun D (1998) Single-channel activations and concentration jumps: comparison of recombinant NR1a/NR2A and NR1a/NR2D NMDA receptors. J Physiol (Lond) 510:1-18. 